\section{A PARABOLA DE PERRY ANDERSON}

\section{ANDERSON'S PARABOLA}

ANDERSON, Perry. (2019), Brazil Apart (1964-2019), Verso, London, 224 páginas, ISBN 978-1-78873-794-4

\section{Fabio Luis Barbosa dos Santos (1)}

E-mail: fabio.luis@unifesp.br.

(1) Professor do Departamento de Relaçóes Internacionais da Universidade Federal de Sáo Paulo.

DOI: $10.1590 / 3610617 / 2021$

A cidadania anglófona que se interessa pelo Brasil deve ser grata por Perry Anderson ter vivido neste país nos anos 1960 e desde entáo, acompanhar e escrever sobre ele. É o caso feliz de um autor que conhece intimamente o país retratado e também a realidade daqueles que o lerão. Nessa condição, realça peculiaridades que um brasileiro tende a naturalizar, ao mesmo tempo em que estabelece, de modo fluido, comparações com o mundo anglo-saxão e além.

Também os brasileiros são privilegiados em contar com as reflexôes de uma das mentes críticas mais brilhantes da contemporaneidade: no caso de Anderson, a condição estrangeira é uma virtude, pois o distanciamento das paixóes políticas locais favorece a crítica sóbria, como demonstrou em sua penetrante análise sobre a Índia (ANDERSON, 2012). As ponderaçóes que seguem têm a ver com diferenças interpretativas, não com o fato de o autor ser estrangeiro.

O título do livro sobre o Brasil pode ser mal interpretado, pois reúne artigos escritos entre 1994 e 2019, e as remissóes à ditadura são sumárias. Com exceção do primeiro texto, elaborado quando Fernando Henrique Cardoso (FHC) iniciava a presidência, e dos mais recentes, escritos quando Bolsonaro começava o seu mandato, os capítulos fazem um balanço das presidências de FHC (1994-2002), Lula (2002-2010) e Rousseff (2010-2016). O conjunto apresenta uma análise abrangente e informada da Nova República, resultando em uma excelente introdução para o leitor estrangeiro, útil também para os brasileiros, sobretudo os jovens. Ninguém lerá esta obra sem aprender e refletir sobre o Brasil.

Os capítulos são preciosos como reconstituição e podem ser lidos individualmente. Mas os liames entre eles, e deles com a ditadura, não são sólidos. Há uma questão de forma, pois as partes foram escritas de modo independente e a costura é posterior tornando inevitáveis algumas repetições. Também há a escolha metodológica de enfatizar aspectos políticos, reconstituídos com particular riqueza nos anos recentes. Mas o aspecto central é de natureza interpretativa. Anderson expóe (quase) todos os elementos fundamentais do período, mas os nexos entre eles nem sempre são explorados e por vezes, contradiçōes emergem. Estabelecer tais nexos implica problematizar continuidades e descontinuidades à luz do sentido geral da história. O núcleo da questão é entender o significado da ditadura, o movimento da história desde entâo, a natureza dos governos petistas e sua derrocada neste quadro.

1.

Primeiro, as continuidades. Focalizando a análise na Nova República, Anderson entende que os governos PT romperam com o neoliberalismo: "Longe de qualquer continuidade, houve um abismo entre o seu governo e aquele de Cardoso"; o PT no poder "se recusou a profundar o regime neoliberal" (ps. 64; 196).

É preciso esclarecer que Anderson não reproduz a narrativa petista: aspectos como a corrupção do partido, o mito de uma "nova classe média" e a natureza desmobilizadora das gestôes petistas, que contribuíram para o que tem sido desde 2015 uma "uma guerra de classe unilateral", são assinalados com propriedade (ps. 152; 194). Apesar do entusiasmo com a análise do cientista político e ex-porta voz do governo Lula, André Singer (2012), há reparos. Anderson não vê "republicanismo" na conduta do judiciário brasileiro sob a Lava-Jato, somente parcialidade ("factious") (p. 155-159). E observa que "medo de desordem $e$ aceitaçâo da hierarquia", racionalizados por Singer para justificar o conservadorismo petista no poder, "são legados da escravidão" (p. 97). Os brasileiros não evitam o conflito por terem natureza dócil, mas por causa da violência brutal que ele mobiliza. 
No entanto, Anderson entende que o Brasil petista se afastou do neoliberalismo, o que é difícil de sustentar. No plano macroeconômico, o tripé meta inflacionária, superávit primário e câmbio flexível estabelecido pelo "Plano Real”, que Anderson identifica como neoliberal, foi mantido, o que levou Leda Paulani a descrever a política econômica do primeiro governo Lula como "a mais completa encarnação" do neoliberalismo (PAULANI, 2008, p. 10). Mesmo a "Nova Matriz Econômica" ensaiada por Rousseff, embora diferente, não rompeu com este paradigma (SCHINCARIOL, 2017). Se entendermos o neoliberalismo como uma tecnologia de governo das pessoas presidida pelo princípio da concorrência (DARDOT e LAVAL, 2010), a continuidade é igualmente evidente. As gestôes petistas promoveram a inclusão pelo consumo como solução para problemas sociais - uma via individual, que mercantiliza direitos. Mesmo o Bolsa família, principal programa social petista, como admite Anderson, apenas consolidou "vários esquemas parciais que já existiam, expandindo sua cobertura" (p. 61).

A certa altura, o intelectual britânico afirma que o manejo de mídias sociais por Bolsonaro se apoia em uma "transformação que beira a revolução social", citando em seguida o alto número de smartphones no país (p. 194). Ao contrário de qualquer "revolução", trata-se de mais uma rodada de modernização dos padrôes de consumo, cuja outra face é a perpetuação da concentração de renda e do mimetismo cultural, fenômeno antigo como o próprio subdesenvolvimento.

Anderson identifica neoliberalismo com "desregulamentação de mercados e privatização de serviços" (p. 33), o que é uma leitura problemática sobre o neoliberalismo e também sobre as administrações do PT: nenhuma privatização foi revertida e formas de mercantilização de serviços públicos foram aprofundadas na saúde (Ebserh), na educação (Prouni) e na previdência (reforma de 2003), para citar exemplos conhecidos. Quanto à regulação da economia, o percentual das importaçóes e exportaçóes em relação ao PIB aumentou, assim como a mobilidade de capitais, o que denota maior abertura comercial e financeira. Esses processos se deram sob o pano de fundo de uma desindustrialização contínua desde os anos 1980: entre FHC e Lula (1994 e 2010), a participação de commodities nas exportaçóes brasileiras elevou-se de $50 \%$ a $64,6 \%$ (ESPOSITO, 2017).

No conjunto, as linhas que Anderson escreveu antes da posse de Lula em 2002, aventando que, talvez no futuro, FHC "ainda poderia se congratular de ter tornado, depois de tudo, a ordem neoliberal irreversivel no Brasil por algum tempo por vir", como Thatcher fez com Tony Blair, parecem acertadas (p. 44).

2.

Sobre as descontinuidades, admitindo que as continuidades foram estruturantes a despeito da alternância política. Se é correta a percepção de que PT (fundado em 1980) e PSDB (em 1988) se constituíram como pólos diferentes, mas complementares da Nova República (à maneira de democratas e republicanos nos Estados Unidos), a Nova República e a Constituição de 1988 estão em xeque.

Este enfoque exige examinar os governos petistas a partir de um ângulo não explorado por Anderson: sua funcionalidade do ponto de vista das classes dominantes. Lula foi eleito em um momento de contestação do neoliberalismo na América do Sul, que envolveu insurreiçôes (derrubando presidentes na Argentina, Bolívia e Equador), mas também o castigo eleitoral: o partido associado ao neoliberalismo no Brasil nunca mais elegeu um presidente. Embora a chamada "onda progressista" fosse identificada corretamente em seu momento como uma reação ao neoliberalismo (SANTOS, 2018), é pertinente indagar, retrospectivamente, se não foi funcional para a reprodução da ordem, em um momento de crise de legitimidade das forças políticas tradicionais.

Esta leitura é ilustrada por um episódio que escapa à análise de Anderson, e seria mesquinho apontar uma omissão em um livro táo abrangente, não fosse ela crucial. No primeiro ano do governo Lula, aprovou-se uma reforma da previdência, emblemática por dois motivos: porque substituiu a lógica da solidariedade geracional (em que os trabalhadores ativos sustentam os aposentados) por um modelo em que cada trabalhador tem uma conta, gerida como um produto financeiro. Mas também porque revelou a capacidade de persuasão do partido no poder, uma vez que a mesma agenda tinha sido 
brecada no governo anterior pela resistência de centrais sindicais e do próprio PT. Em outras palavras, o PT realizou na conversa o que o governo anterior não conseguira na marra.

A corrosão deste "modo lulista de regulação do conflito social" é fundamental para entender o deslizamento da política brasileira para a direita (BRAGA e SANTOS, 2020). A análise de Anderson salienta, corretamente, a baixa nos preços das commodities que se desdobra em recessão a partir de 2014, e a escalada de escândalos de corrupção, geridos como espetáculos televisivos por um judiciário antipetista com apoio da mídia corporativa. Porém, para compreender a movimentação dos de cima, é preciso integrar à análise o impacto das Jornadas de Junho de 2013, cuja importância é subestimada no livro. O maior ciclo de protestos populares desde o fim da ditadura chacoalhou o país, escancarando o esgotamento da paz petista. A sugestão de Anderson de que há uma continuidade entre as jornadas de junho e as manifestaçóes pró-impeachment nos anos seguintes é contrariada por pesquisas sobre o perfil dos manifestantes (BADARÓ, 2015), e só é sustentada por setores obtusos do petismo. Um raro lapso no olhar arguto do autor.

O resultado desta convergência de aspectos sociais (jornadas de junho), políticos (corrupção) e econômicos (recessão) é um deslizamento na abordagem das classes dominantes vis à vis a reprodução social, que pode ser resumido em duas ideias: a passagem de um neoliberalismo inclusivo para a espoliação social, e da conciliação para a guerra de classes. É este o pano de fundo da deposição de Rousseff, da prisão de Lula e da eleição de Bolsonaro. Para além dos personagens, a classe dominante disputa a cara do arranjo político, jurídico e cultural que substituirá a Nova República, definitivamente condenada. A dispersão de candidatos na eleição de 2018 é um sintoma desta busca por um caminho, como na eleição de Collor de Melo há trinta anos, quando a Nova República começava. Entre estas duas eleições, todos os pleitos foram polarizados entre PT e PSDB.

Nesta chave, há um componente acidental na eleiçâo de Bolsonaro, que se revelou como o único capaz de vencer o PT nas urnas. Anderson expóe esta fragilidade, quando encerra o livro cogitando a possibilidade de um impeachment. Mas o significado profundo da eleição do ex-capitão não é explorado. Penso que, para além da fachada militar, este governo é a versão brasileira de um fenômeno mundial, em que as afinidades entre neoliberalismo e autoritarismo são cada vez mais explícitas (DARDOT e LAVAL, 2018). Como lembra Anderson, sequer são necessários tanques nas ruas, uma vez que "a democracia há muito se tornou segura para o capital” (p. 214).

Em consonância com esta observação, Bolsonaro pode ser visto como a caricatura de uma tendência global - caricatura no sentido de que exagera os traços de uma fisionomia política que se normaliza. A alta burguesia brasileira acha Bolsonaro desagradável, opiniáo compartilhada por Marine Le Pen. Seu ideal é outro: argumentei que estão à procura de um bolsonarismo sem Bolsonaro, talvez o seu Macron (SANTOS, 2020). Entretanto, o ex-capitão tem ideias próprias, e seu plano parece ser uma dinastia (tem 3 filhos na política), com os militares e as polícias como partido, e os neopentecostais como base orgânica.

Em suma, Bolsonaro pode ser visto como expressão de uma inflexão das classes dominantes, que à sua maneira, é uma ruptura. Mas uma que vem de dentro e portanto, é muito diferente do golpe que derrubou Goulart em 1964. Há numerosas linhas de contato entre os governos petistas e a ascensão de Bolsonaro, mapeadas mas pouco exploradas na obra: o neopentecostalismo, o PMDB, o vice-presidente golpista Michel Temer, os militares, a mídia corporativa, os bancos, o agronegócio - todos alimentados e cultivados, em seu momento, pelos governos petistas. Nesta realidade, a figura de imagem mais adequada não é uma guinada de 180 graus, mas uma metástase, na medida em que forças e interesses corrosivos cujo poder nunca foi desafiado e que pareciam controladas sob o petismo, agora se espalham inconteste pelo tecido nacional.

\section{3.}

Esta constatação leva a uma derradeira continuidade, na qual se inscreve o processo histórico entre 1964 e 2019 como uma totalidade. No último capítulo, Anderson evoca de modo ácido a participação militar brasileira na missão da OEA na República Dominicana 
em 1965, quando começava a ditadura, relacionando-a à chefia da missão da ONU na mesma ilha quarenta anos depois sob Lula, desta vez no Haiti - ambas em consonância com o interesse dos Estados Unidos. É um dos melhores momentos do livro. Anderson faz conexôes pertinentes entre esta segunda missão e a ascensão recente dos militares, que ocupam mais cargos de alto escaláo sob Bolsonaro do que na ditadura. Para o intelectual britânico, o retorno dos militares configura uma parábola: "A situação e o regime não são os mesmos. Mas a curva geral da história, do começo ao fim destes cinquenta anos, forma uma parábola uma parábola que dá forma à narrativa e um título à conclusão do que segue - isso é claro" (p. XV).

Entendo que as relaçóes sugeridas por Anderson podem ser exploradas com mais profundidade, revelando outra geometria. Historicamente, os militares brasileiros associaram seu poder à industrialização, entendida como premissa da soberania. Não é casual que a industrialização do país ocorreu entre duas ditaduras - o Estado Novo (1936-1947) e a mais recente (1964-1985). Esse último regime apostou em aprofundar a industrialização, integrar o país com massivas obras de infraestrutura, expandir a fronteira agrícola, colonizar (ocupar e explorar) o interior e a Amazônia, instalar usinas nucleares, desenvolver o etanol, entre outros, nos marcos de um projeto de liderança regional. A ditadura cultivou a utopia de um "Brasil Potência".

Meio século depois, os militares jogaram a toalha. Confrontados com a regressão da estrutura produtiva e a degradação do tecido social brasileiro, abandonaram qualquer projeto de nação, quanto mais de uma potência internacional. Lula enviou os militares para o Haiti pensando em fazer do Brasil um global player. Porém, os militares voltaram pensando em como evitar que o Brasil virasse um Haiti. Agora, arregaçam as mangas para uma gestão militarizada da vida social.

Nesta perspectiva, as administrações petistas podem ser vistas como a última encarnação de um "Brasil Potência" que evocou, não por acaso, um "neodesenvolvimentismo" como ideologia. No entanto, o Brasil não é mais aquele dos anos 1960. Como disse Roberto Schwarz, intelectual que Anderson admira, o desenvolvimentismo foi uma boa ideia até que nos anos 1980 acabou o dinheiro (SCHWARZ, 1999). Para parafraseá-lo, diria que o desenvolvimentismo no século XXI tornou-se uma "ideia fora do lugar", porque o Brasil mudou e o mundo também.

No Brasil, estas mudanças remetem a um processo histórico que tem como ponto de inflexão precisamente a ditadura. Porque por trás do verniz nacionalista, o regime se assentou em uma dissociação entre povo (democracia) e desenvolvimento (capitalismo), comprometendo a possibilidade de um país economicamente autodeterminado, socialmente equitativo, politicamente soberano e culturalmente autorreferido. Se entendermos as ditaduras como um capítulo sul-americano da tensão entre revoluçãa e contrarrevolução sob a Guerra Fria, aventaremos com o sociólogo Florestan Fernandes, que o que se impôs foi a contrarrevolução permanente, inviabilizando a nação (FERNANDES, 1975).

Nesta chave, há uma continuidade entre o caráter antipopular, antidemocrático e antinacional da ditadura, a abertura democrática controlada, e os múltiplos constrangimentos políticos, econômicos e militares que marcam a Nova República. Mencionemos uma conexão epidérmica: a polícia militar foi uma criação da ditadura que permanece incólume, enquanto o neopentecostalismo foi insuflado pelos Estados Unidos contra a teologia da libertação durante a Guerra Fria. Ambos se articulam ao bolsonarismo no presente, escorados em forças armadas que nunca foram responsabilizadas pelos crimes que cometeram.

Visto sob o prisma da contrarrevolução permanente, constata-se não uma parábola, mas um declive contínuo em direção à uma sociedade segregada, violenta e dependente - o "Brazil apart" que dá título ao livro. As administraçóes petistas pretenderam arrefecer este movimento da história suavizando sua inclinação, sem jamais questionar o trilho. Bolsonaro muda a marcha, dobra a curva da Nova República e o acelera.

\section{Referências}

ANDERSON, Perry. (2012), The Indian ideology. New Delhi, Three Essays Colective.

BADARÓ, Marcelo. (2015), "Junho e nós: das jornadas de 2013 ao quadro atual”, Blog Junho, disponível em: 
http://blogjunho.com.br/junho-e-nos-das-jornadas-de2013-ao-quadro-atual/. Acessado em 2 de junho de 2020.

BRAGA, Ruy; SANTOS, Fabio Luis Barbosa dos. (2020), "The political economy of lulismo and its aftermath". Latin American Perspectives. Issue 230, volume 47, n. 1.

DARDOT, Pierre; LAVAL, Christophe. (2010), La nouvelle raison du monde. Essai sur la societé neoliberal. Paris, La Découverte.

DARDOT, Pierre; LAVAL, Christophe. (2018), Anatomie du nouveau néolibéralisme. Avant-propos pour la traduction anglaise de Ce Cauchemar qui n'en finit pas (à paraître).

ESPOSITO, Maurício. (2017), 'Desindustrialização do Brasil: uma análise a partir da perspectiva da formação nacional". Revista da Sociedade Brasileira de Economia Política, n. 46.

FERNANDES, Florestan. (1975), A revolução burguesa no Brasil. Rio de Janeiro, Zahar.

PAULANI, Leda. (2008), Brasil delivery. São Paulo: Boitempo.
SCHINCARIOL, Vitor. (2017), Economia e politica econômica no governo Dilma (2011-2014): uma história política-econômica da primeira administração de Dilma Rousseff. São Paulo, Tricontinental.

SANTOS, Fabio Luis Barbosa dos. (2018), Uma história da onda progressista sul-americana (1998-2016). Sáo Paulo, Elefante.

SANTOS, Fabio Luis Barbosa dos. (2020), L'espoir vaincu par la peur. De Lula a Bolsonaro. Paris, Syllepse.

SCHWARZ, Roberto. (1999), Fim de século. In: Sequências brasileiras: ensaios. São Paulo, Cia. das Letras.

SINGER, André. (2012), Os sentidos do lulismo. Reforma gradual e pacto conservador. São Paulo, Companhia das Letras.

Resenha recebida em: 12/06/2020

Aprovada em: 28/07/2020 